\title{
Product Innovativeness Dimensions and Their Relationships with Product Advantage, Product Financial Performance, and Project Protocol
}

\author{
Regina C. McNally, Erin Cavusgil, and Roger J. Calantone
}

A considerable body of research informs the relationship of product innovativeness with firm and environmental variables as well as the impact of product innovativeness on product financial success. While providing significant insight, the extant literature exhibits conflicting findings that raise questions as to how, specifically, product innovativeness contributes to product financial performance. This study ties together several streams of research related to the product innovativeness construct to enhance understanding of the product innovativeness-product financial performance relationship. The product innovativeness construct is deconstructed by conceptualizing the relationships among three dimensions of product innovativeness: technological discontinuity, marketing discontinuity, and customer discontinuity. Product innovativeness is distinguished from product advantage, and the relationships among product innovativeness dimensions, product advantage, and product financial performance are empirically tested. The results reveal that, indeed, product innovativeness consists of three separate dimensions that exhibit no or moderate correlations with product advantage. Furthermore, product advantage positively and marketing discontinuity negatively influence product financial performance. Finally, the study also examines how project protocols impact the product innovativeness dimensions. Project protocols, also known as product definitions, describe the general parameters a new product should exhibit (i.e., target segments, product functions and features, base technology, pricing, communication and distribution channels, and required resources) as well as the priorities of the general parameters. Because they guide product design and set priorities and have been found to be a dominant driver of product financial performance, project protocols are important. The present study enhances understanding of how project protocols influence the dimensions of product innovativeness, finding that project protocols positively impact product financial performance indirectly through product advantage and marketing discontinuity.

\section{Introduction}

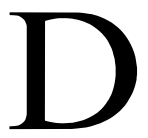
eveloping innovative new products is the cornerstone to success in many industries. Given the managerial importance, it is no surprise that multiple meta-analyses have been published examining the impact of product innovativeness on product financial performance (Henard and Szymanski, 2001; Szymanski, Kroff, and Troy, 2007). While this research offers significant insight, conflicting findings continue to raise questions as to specifically how product innovativeness contributes to product financial performance, for example, the range of innovativeness: performance correlations reported in these meta-analyses encompass positive, insignificant, and negative values. In addition, the main effect is insignificant (Henard and Szymanski), most likely

Address correspondence to: Regina C. McNally, Department of Management and Marketing, Kemmy Business School, University of Limerick, Limerick, Ireland. Tel.: +353.61.234605. Fax: + 353 . 61.213196. E-mail: regina.mcnally@ul.ie. due to contingencies related to various measurement and contextual factors (Szymanski et al.). The significant measurement factor regards the definition of innovativeness and its subsequent operationalization. Often innovativeness is defined as newness (Garcia and Calantone, 2002) and is operationalized as such (e.g., Cooper, 1979). However, innovativeness also has been operationalized as newness and customer meaningfulness (de Brentani, 1989), which results in a stronger association with performance than when the operationalization encompasses just newness (Szymanski et al.). Notably, in this meta-analysis the newness plus meaningfulness operationalization is the single correlation of the 28 examined to exhibit a range encompassing only positive values. Significant contextual factors include new-to-the-market rather than new-to-the-firm and goods-related rather than goods and services innovations, which are associated with improved performance, whereas more recent innovation efforts are associated with decreased performance (ibid.). Thus, questions remain regarding the 
relationship between product innovativeness and product financial performance.

The present study probes this relationship further by taking a deeper look at the product innovativeness construct, disaggregating it into three separate dimensions. Following Danneels and Kleinschmidt (2001) and Garcia and Calantone (2002), product innovativeness is considered in the present study from the perspectives of both firms and customers. Regarding the firm's view of product innovativeness, "what is new" is examined by splitting product innovativeness into the two dimensions of technological discontinuity and marketing discontinuity. Product innovativeness from the firm's perspective is defined as the potential discontinuity a product can generate in firms' technological processes and in firms' marketing processes.

Regarding the customers' perspective, a third dimension of product innovativeness is employed - customer discontinuity - which is the extent to which customers are required to change or adapt behavior patterns when adopting a new product (Danneels and Kleinschmidt, 2001). In considering customer discontinuity, the literature surrounding consumer reluctance to adopt innovative products is explored. While innovative products can offer significant benefits to consumers, the novelty and unfamiliarity of

\section{BIOGRAPHICAL SKETCHES}

Dr. Regina C. McNally is lecturer in the Department of Management and Marketing at the Kemmy Business School at University of Limerick, Ireland. She received a Ph.D. in business, specializing in marketing, from the University of Illinois at Urbana-Champaign. Her research interests focus on the processes and outcomes of strategic firm decisions, such as new product development, investigating the factors that drive the choice of different alternatives, and the performance outcomes of such decisions. Of special interest is the role of both economic factors and social factors in such decisions. She has published in Journal of Product Innovation Management and Journal of the Academy of Marketing Science, among others.

Dr. Erin Cavusgil is assistant professor at the University of Michigan-Flint. She holds a B.S. in chemical engineering from the University of Michigan, an M.S. in biomedical engineering from the University of Minnesota, and a Ph.D. in marketing from Michigan State University. She spent $31 / 2$ years working in the pharmaceutical industry as a chemical engineer. Her main research interests include new product development, innovation, and marketing strategy. Her research has been published in Journal of Product Innovation Management, Journal of Business Ethics, and Journal of Business Research, among others.

Dr. Roger J. Calantone is the Eli Broad University Professor of Business at Michigan State University. He is also adjunct professor of economics and director of the program in Information Technology Management. His research is focused on product innovation strategy and decision making. such products can diminish consumer acceptance, lowering performance. Innovative products that offer a high level of discontinuity, such as changing customers' consumption habits or requiring learning, are likely to exhibit slower adoption by consumers (Rogers, 1995). Therefore, further insight is provided into why, under certain circumstances, product innovativeness may hinder product financial performance.

Although product innovativeness does not exhibit a main effect on product financial performance, other antecedents are found to be dominant drivers (Henard and Szymanski, 2001; Montoya-Weiss and Calantone, 1994). Two particular antecedents of product financial performance are examined here: product advantage and project protocols. Product advantage is superiority over or differentiation from competitive offerings (Henard and Szymanski). Considerable research demonstrates that product advantage is a crucial driver of product financial performance (Calantone, Chan, and Cui, 2006; Henard and Szymanski; Langerak, Hultink, and Robben, 2004; Li and Calantone, 1998; Montoya-Weiss and Calantone; Song and Parry, 1996; Veldhuizen, Hultink, and Griffin, 2006). Project protocols, also known as product definitions, describe the general parameters the new product should exhibit (i.e., target segments, product functions and features, base technology, pricing, communication and distribution channels, and required resources) along with the priorities of the general parameters (Bacon et al., 1994; Crawford, 1984; Khurana and Rosenthal, 1997; Montoya-Weiss and Calantone). Project protocols are important because they guide product design and set priorities so that subsequent decision makers can efficiently create advantageous products (Bacon et al.). Despite their importance, however, implementation is problematic given the difficulty in assessing the necessary parameters and priorities (Karlsson, Nellore, and Soderquist, 1998; Khurana and Rosenthal). Thus, product advantage and project protocols also are included in this research to examine their role in product financial performance when accounting for the three dimensions of product innovativeness.

Meta-analyses are useful for identifying overall associations between a single dependent variable, such as product financial performance, and multiple independent variables. However, they generally do not test more complex relationships among the independent variables that arise when mediation is considered. The mediated relationships among the independent variables modeled here are intended to address this gap. 
Doing so advances our understanding of how these dimensions relate to each other and to product financial performance, answering the call of Szymanski et al. (2007) for more complex models of innovativeness.

This paper proceeds as follows. First, the construct of product innovativeness is examined to separate it into three discontinuity dimensions and distinguish it from product advantage, a construct often bundled inappropriately with product innovativeness. Next, hypotheses are offered that explain how the three dimensions relate to each other and to firm performance, product advantage, and the use of project protocols. Then, the research method is described, and the analysis results are summarized. Finally, the paper concludes with a discussion of the importance of the results for both researchers and managers.

\section{Product Innovativeness}

Meta-analysis results suggest there is no direct main effect of product innovativeness on product financial performance (Henard and Szymanski, 2001; Szymanski et al., 2007). Despite this empirical result, there are reasons to believe that the relationship between product innovativeness and product financial performance should be statistically significant. Logic supporting a positive relationship suggests the newness and uniqueness of innovative products can garner greater opportunities for differentiation and may be patentable, perhaps providing a sustainable advantage over competitors (Kleinschmidt and Cooper, 1991; Song and Parry, 1996). Supporting a negative relationship, highly innovative products are less familiar to firms and consumers, thus entailing more risk, greater possibility of something going wrong, less likelihood of customer adoption, and ultimately a greater likelihood of financial failure (Kleinschmidt and Cooper).

Empirical evidence exists for both arguments (Henard and Szymanski, 2001) as well as for no significant relationship (Calantone et al., 2006; Calantone, Di Benedetto, and Bhoovaraghavan, 1994). Calantone et al. (2006) find that product innovativeness has no direct effect on product profitability. Employing the theory of expected utility, these authors suggest that the mediating effects of product advantage and customer discontinuity fully capture the effect of product innovativeness on performance; therefore, no direct effect should be expected. Kleinschmidt and Cooper (1991) demonstrate a nonlinear (U-shaped) relationship between innovativeness and performance, sug- gesting a moderated relationship. They conclude that high- and low-innovativeness products are more likely to be successful than those of moderate innovativeness due to differences in product advantage, synergies, and poor implementation of predevelopment activities. Supporting the explanation regarding highly innovative products, Gatignon et al. (2002) find that technologically discontinuous innovations are associated with commercial success. Thus, the extant research suggests that the role of product innovativeness in explaining product financial performance is not straightforward. Disaggregating product innovativeness into multiple dimensions will help reveal its complex relationship with product financial performance.

Scholars have offered various conceptual configurations of product innovativeness. An early conceptualization developed by the Boston Consulting Group considers the level of newness from the perspective of the market as well as from the perspective of the firm. Danneels and Kleinschmidt (2001) and Garcia and Calantone (2002) expand this conceptualization, examining not only from whose perspective product innovativeness is viewed (i.e., the firm vs. the customer) but also what is new to the firm (i.e., technology vs. market). Consistent with their conceptualization, the product innovativeness concept from the firms' perspective is deconstructed into the two separate dimensions of technological discontinuity and marketing discontinuity. Technological discontinuities arise from operating in new technological domains and involve new processes or technologies associated with the innovation, such as new development technology (e.g., that associated with nanotechnology), new development processes, new manufacturing equipment, or new manufacturing processes. Marketing discontinuities, on the other hand, arise from operating in new marketing domains and result when, for example, the product category, competitors, distribution channels, or customers are unfamiliar to the firm. Much empirical literature, even recent research (e.g., Salomo, Weise, and Gemunden, 2007), does not separate innovativeness into technological and marketing factors.

When considering from whose perspective the newness of an innovative product is examined, the customer's perspective of a product's innovativeness can be distinguished from the firm's perspective (Danneels and Kleinschmidt, 2001; Garcia and Calantone, 2002). From the customer's perspective, product innovativeness depends on the innovation's attributes 
(relative product advantage, compatibility, complexity, trialability, and observability), risk associated with adoption, and level of behavioral change required on adoption of the innovation (Danneels and Kleinschmidt). Given the discontinuity focus of this manuscript, the extent of behavioral changes required of customers when they adopt innovative products is addressed. Furthermore, product advantage is conceptualized as a separate construct from customer discontinuity to examine the relationships among the innovativeness and product advantage constructs.

Particularly when examining innovativeness from the customers' perspective, measures of product advantage often are bundled inappropriately with product innovativeness (Calantone et al., 2006). Product advantage refers to a product's superiority over other products in the customers' eyes based on quality, delivered benefits, and economic advantage and has long been recognized as a crucial driver of new product performance (Cooper and Kleinschmidt, 1986; Rogers, 1995). Prior research demonstrates that product innovativeness is significantly associated with product advantage (Kleinschmidt and Cooper, 1991) and that product advantage is not a significant moderator of the product innovativeness-financial performance link (Szymanski et al., 2007). Both firm discontinuity dimensions and product advantage may generate a level of newness from the customers' perspective that forces undesired behavioral changes on their part, potentially leading to consumer reluctance to adopt. By examining the three dimensions of product innovativeness from a discontinuity perspective, the roles of discontinuity and product advantage are separated, and how these factors impact product financial performance is examined.

Other terms have been used to capture aspects of innovativeness and also exhibit lack of disaggrega- tion. Radical innovations, juxtaposed with incremental innovations, are new products based on new technology and offering new benefits to customers (Chandy and Tellis, 2000). This definition encompasses the present study's technological discontinuity and product advantage dimensions. Despite this definition, conceptualization and operationalization discrepancies exist. For example, Govindarajan and Kopalle (2006) define radical innovations as relating only to technology, whereas Gatignon et al. (2002) employ only the technological discontinuity dimension in their operationalization. Another term used is that of breakthrough innovations. Often considered to be synonymous with radical innovations (Sood and Tellis, 2005), others consider breakthrough to be related to both customer discontinuity and product advantage by defining breakthrough innovations as new products that are first to bring novel and significant benefits to consumers (Chandy and Tellis, 1998; Sorescu and Spanjol, 2008). Thus, despite the appearance of multiple terms associated with innovativeness, the three-dimensional disaggregation of product innovativeness and the separation from product advantage used in this research incorporates the fundamental definitions and distinctions appearing across the various terms.

\section{Model and Conceptual Development}

In this section, the hypotheses delineating the relationships among the three dimensions of product innovativeness as well as the dimensions' relationships with product advantage, product financial performance, and project protocols are developed. Figure 1 provides a model of the hypothesized relationships.

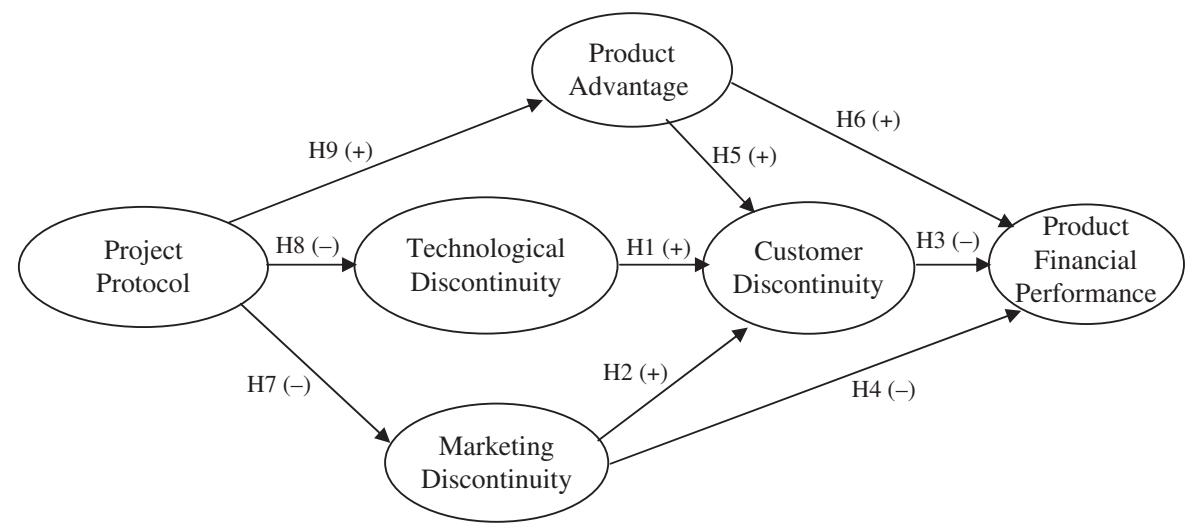

Figure 1: The Hypothesized Model 
Customer discontinuity is the extent to which customers are required to change or adapt behavior patterns when adopting a new product (Danneels and Kleinschmidt, 2001). Prior research exploring the psychological factors contributing to consumer adoption of new products finds that highly innovative new products often require significant behavioral changes by the consumer (Moreau, Lehmann, and Markman, 2001). Inherent in these products is a certain level of uncertainty and risk associated with the innovation as well as learning required to comprehend the new product (Saaksjarvi, 2003). Such innovations are likely to be unfamiliar to consumers, making it difficult for consumers to understand their benefits (Min, Kalwani, and Robinson, 2006; Veryzer, 1998). Consumers have greater uncertainty when estimating the usefulness of highly innovative products compared with less innovative new products (Hoeffler, 2003). This literature suggests that products exhibiting customer discontinuity (a) can be perceived as risky by the consumer and (2) require significant learning or behavior changes upon adoption of the product.

Technological discontinuities arise when firms operate in new technological domains related either to technologies associated with the innovation itself or to new processes associated with development and production. In such situations, technological uncertainty is high in that firm individuals perceive they are unable to accurately predict or completely understand some aspect of the technological environment (Song and Montoya-Weiss, 2001). As these researchers report, high technological uncertainty attenuates firm members' ability to transform the technical synergy associated with technically related projects into technical proficiency and ultimately financial performance. Products exhibiting superior technical performance and excellent research and development (R\&D) organization are two of the most important dimensions in predicting product failure or success in the marketplace (Zirger and Maidique, 1990). Furthermore, dedicated individuals and informal networks are crucial in moving radical innovations from idea to commercialization (O'Connor and McDermott, 2004). However, new technologies not only create uncertainty regarding the technology itself but also change organizational structures and communication patterns that disrupt firms' abilities to successfully commercialize highly innovative products (Tushman and Romanelli, 1985). The uncertainty and disruption associated with technological discontinuity potentially make it more difficult for firms to design and implement products that fit neatly into customers' current consumption patterns. Thus:

H1: Technological discontinuity will have a positive impact on customer discontinuity.

Marketing discontinuities, on the other hand, arise when firms operate in new marketing domains and result when, for example, the product category, competitors, distribution channels, or customers are unfamiliar to the firm. Competent marketing is an important dimension in predicting product success (Zirger and Maidique, 1990), particularly in unfamiliar markets (Souder and Song, 1998). However, uncertainty attenuates firm members' ability to transform the marketing synergy associated with projects related to current markets and marketing tasks into marketing proficiency (Song and MontoyaWeiss, 2001). Research into proactive market orientation, often associated with development of highly innovative new products, provides further insight into the marketing discontinuity-customer discontinuity relationship. Proactive market orientation focuses on satisfying unarticulated, latent customer needs via research methods enabling deep customer understanding, experimentation, and willingness to cannibalize (Atuahene-Gima, Slater, and Olson, 2005). These researchers find that proactive market orientation exhibits an inverted-U shaped relationship with new product performance, supporting prior anecdotal evidence that too much future-oriented research may hurt new product development (NPD) performance. As Atuahene-Gima et al. suggest, an overabundance of exploratory projects may reduce managers' ability to deliver products that effectively build on customers' existing knowledge and processes. Therefore,

\section{H2: Marketing discontinuity will have a positive impact on customer discontinuity.}

The present study argues that new products offering a high level of either marketing or technological discontinuity are less likely to be accepted by consumers and therefore less successful in the short-term. Given the perceived risk (Holak and Lehmann, 1990) and greater uncertainty (Hoeffler, 2003), consumers are less likely to intend to purchase discontinuous innovations compared with continuous innovations (Alexander, Lynch, and Wang, 2007). In fact, based on standardized regression coefficients, compatibility with current knowledge and processes appears to be at 
least as impactful in purchase intention formation as product advantage (Holak and Lehmann), whereas benefit comprehension also is important in customer preference formation (Moreau et al., 2001). Another reason highly innovative products are unattractive to consumers is due to the myopic search consumers exhibit in both familiar and novel product contexts (Hoeffler, Ariely, and West, 2006). That is, when trying various alternatives of new products to find the one best matching their preferences, consumers tend to emphasize short-term gains (i.e., quickly finding favorable alternatives while minimizing negative product experiences) rather than emphasizing the long-term benefits of learning about a wide range of alternatives to find the best possible one. This myopic search process results in adoption of products that do not require extensive learning or behavior changes, suggesting that increased customer discontinuity will lower product adoption and, thus, product financial performance. Thus, the conceptual notion of myopic search and empirical research suggests the following:

\section{H3: Customer discontinuity will have a negative impact on product financial performance.}

Market knowledge and marketing proficiency, along with marketing synergy, have long been recognized as important contributors to new product success (Cooper, 1979). Market knowledge has been referred to as familiarity (Danneels and Kleinschmidt, 2001) and is important because it helps marketing managers understand how to communicate and interact effectively with target customers. Product success is more likely in familiar markets (Souder and Jenssen, 1999; Souder and Song, 1998). However, lack of familiarity does not doom a firm to failure as synergy, or "fit," also matters (Danneels and Kleinschmidt). Synergy suggests that existing marketing skills and resources can be applied in unfamiliar markets. Supporting this notion is research by Song and Parry (1997b), who find that marketing skills and resources are significantly associated with proficiency in multiple stages of new product development, including idea development and screening, market opportunity analysis, product testing, and commercialization. They also find that marketing skills and resources positively moderate the association between product differentiation and various product performance measures in both the United States and Japan. In addition, marketing fit, which relates to the postlaunch activities regarding adequacy of existing sales force, advertising and promotion, marketing research, and customer service people, skills, and resources, is significantly related with new product success (Danneels and Kleinschmidt). Thus, both the familiarity and fit ideas associated with the application of marketing skills and resources suggest that new product success is more likely when the firm is either familiar with the target market or has skills and resources that can be adapted to the target market. However, when familiarity and fit are low, as in the case of marketing discontinuities, new product success is more difficult to achieve. Thus,

\section{H4: Marketing discontinuity will have a negative impact on financial performance.}

\section{Product Advantage}

Products offering a significant advantage over competitors' products also tend to be unique. Radical new products are more differentiated from competitors' products and have a greater product advantage (Gatignon and Xuereb, 1997), yet consumers exhibit more uncertainty about these types of innovations (Hoeffler, 2003). Use of such products may require learning by the consumer (Carpenter and Nakamoto, 1989), and customers often must alter their behaviors to obtain the benefits offered (Dahl and Hoeffler, 2004). Unless highly innovative products can be explained in terms analogous to familiar products, customers lack a frame of reference to understand the product and its use and may undervalue the product benefits (Moreau et al., 2001; Veryzer, 1998). Marketing researchers use visualization, a form of cognitive processing in which visual information is represented in working memory (MacInnis and Price, 1987), to overcome consumer difficulties in understanding product benefits. Highly innovative products are perceived more favorably when consumers visualize others using the product rather than visualizing themselves using it (Dahl and Hoeffler). These authors speculate that, because consumers find it more difficult to picture themselves using the innovation than it is to picture others doing so, the inability to visualize how the product fits in the consumers' own lifestyles decreases their preferences for the product. When visualizing themselves using the product, imagining new uses leads to higher preferences for highly innovative products than when thinking of using the product in existing contexts, and imagining about product benefits leads to higher 
preferences than imagining about learning costs (Zhao, Hoeffler, and Dahl, 2009). Thus, products offering significant advantages are likely to be perceived as novel to the customer, creating difficulties for customers to understand how such products fit in their lifestyle, particularly when potential customers cannot visualize themselves using the product. Therefore,

\section{H5: Product advantage will have a positive impact on customer discontinuity.}

Although product advantage potentially reduces product financial performance via customer discontinuity, at the same time having superior products relative to competitors can enhance performance. Early work in this area found product advantage (uniqueness and superiority) to be the single most important dimension leading to new product success (Cooper, 1979). A number of subsequent studies have confirmed this result and found a positive association between product advantage and performance (Calantone et al., 2006; Langerak et al., 2004; Li and Calantone, 1998; Song and Parry, 1996; Veldhuizen et al., 2006). In their meta-analysis of predictors of new product performance, Henard and Szymanski (2001) find that product advantage has a significant impact on new product performance. Similarly, Montoya-Weiss and Calantone (1994) identify product advantage as one of the strategic factors most strongly linked to performance. It is evident from the existing literature that product advantage has a strong and positive impact on performance. Products meeting customers' needs better than competitive offerings ultimately experience marketplace success. Therefore,

H6: Product advantage will have a positive impact on financial performance.

\section{Project Protocols}

In identifying crucial activities to enhance project success and firm performance, Crawford (1984) suggests creation of and cross-functional agreement on a project protocol, which he defines as a document listing the benefits the product should deliver. Since then, others have expanded the definition of project protocol to encompass firms' knowledge and understanding of specific marketing and technical aspects related to the ability to deliver a superior product (MontoyaWeiss and Calantone, 1994). These aspects include well-defined target markets, product functions and features, base technology, pricing, communication and distribution channels, and required resources as well as the priorities of all these aspects. Cooper and Kleinschmidt (1987) add product positioning as an important component of a project protocol. Empirical research finds that the presence of a project protocol is significantly associated with multiple measures of firm performance (Cooper and Kleinschmidt; MontoyaWeiss and Calantone). Rather than operating directly on product financial performance, however, project protocols are hypothesized to operate indirectly through marketing discontinuity, technological discontinuity, and product advantage.

Proficiency in the front-end activities of development process planning and understanding marketing and technology trends is positively associated with new product market and financial performance (Langerak et al., 2004). Salomo et al. (2007) expand on how proficiency in front-end activities results in improved product financial performance. They find that goal stability and goal clarity are both important predictors of product financial performance, exhibiting main effects on the dependent variable that are not moderated by product innovativeness. Goal clarity is important in both developing and maintaining competitive advantage as it helps firms sustain a dynamic capability in developing and commercializing radical and really new innovations (O'Connor, 2008). Furthermore, proficient predevelopment business planning drives product financial performance indirectly through proficient project planning, proficient risk planning, and goal stability (Salomo et al.).

Project protocols are important because developing a product with benefits valued by customers depends on them (Khurana and Rosenthal, 1997). They are particularly important when operating in new marketing domains, as occurs under conditions of marketing discontinuity, because they ensure that firms fully assess customer needs vis-à-vis product features and functions, pricing, and communication and distribution channels. Furthermore, because project protocols describe and prioritize marketing and technical goals, they provide a platform on which consensus can be built among senior managers and new product development staff (Bacon et al., 1994). As a result, they play an important role in achieving goal clarity and stability, particularly in unfamiliar markets. Thus, protocols are a crucial process activity to 
manage effectively the uncertainty associated with NPD projects in new marketing domains. Thus,

\section{H7: Project protocols reduce marketing discontinuity.}

As defined previously, technological discontinuities arise when firms operate in new technological domains related either to technologies associated with the innovation itself or to new processes associated with development and production. Technical proficiency directly impacts new product success, and one way to increase technical proficiency is by choosing projects that fit current technological capabilities (Song and Parry, 1997a). Another way is to conduct a full assessment of the availability and reliability of technologies used in the product or in its manufacture, which is an important input to project protocols (Bacon et al., 1994). These researchers find that, frequently, products requiring significant advances in underlying technologies during development fail. For successful projects, the project protocol technology assessment involves determining the degree of risk associated with technology options and planning for the associated risks (ibid.). Firms can manage these risks via contingency planning, such as developing alternative technologies in parallel (Khurana and Rosenthal, 1997). Developing the project protocol, then, allows firms to make a full assessment of the viability of required technologies and to develop contingency plans associated with risky technology. Thus, the uncertainty associated with technological discontinuity can be minimized via project protocols, as hypothesized:

\section{H8: Project protocols reduce technological discontinuity.}

Product advantage refers to a product's superiority over other products based on, for example, quality, benefits, or value (Cooper and Kleinschmidt, 1986). The intent of project protocols is to deliver superior products to the marketplace, as empirical research finds: the timely and reliable customer information related to user needs and wants contained in the project protocol was the most critical information for successful product development (Bacon et al., 1994). Front-end NPD activity research also supports the positive relationship between project protocols and product advantage. Proficiency in front-end activities such as idea development and screening and opportunity analysis result in differentiated products and ultimately, assuming competent marketing skills and adequate marketing resources, product financial suc- cess (Song and Parry, 1997b). Market orientation, as exhibited in a firm culture where collecting and disseminating customer and competitor information are crucial components of new product development, results in greater product advantage and ultimately product financial success (Langerak et al., 2004). Research by Veldhuizen et al. (2006) supports the positive association between market information processing and product advantage. Therefore,

\section{H9: Project protocols enhance new product advantage.}

Now, the research method used to test the hypotheses is discussed.

\section{Research Method}

\section{Sample and Data Collection}

A survey method was used to gather data to empirically test the hypotheses. Respondents were randomly selected from a proprietary list of managers from the biochemical, chemical, and pharmaceutical industries in North America. A professional survey research firm owns the list and created the sample by randomly selecting 700 firms from the list. Respondents included new product development managers, product development managers, product line managers, and product managers. The survey was administered by the professional survey research firm employing callbacks and incentives to obtain cooperation. Multiple survey mailings were sent to managers at the sample firms with a small monetary amount enclosed to encourage subjects to complete the survey. Respondents also were offered a report summarizing the results in return for their participation. As a result, 444 usable responses were received for a response rate of $63 \%$.

To enhance validity, respondents focused their responses on a single, recently launched product rather than summarizing the situation for all products. Specifically, respondents were instructed to identify a new product launched within the prior five years and to respond to the items as they relate to that particular new product. Several items assessed the projects respondents rated, including the main source of the new product idea (technology, customers, competitive products, suppliers, and other), whether the idea was driven by technology (i.e., technology push) or the market (i.e., market pull), and the degree of innovativeness of the product. The sample is composed of ideas predominantly sourced 
from technology $(n=178 ; 40 \%)$ or customers $(n=126$; $28 \%$ ). The mean of the technology-push versus marketpull item is 5.64 with a standard deviation of 2.97, where 0 means the idea was driven by technology and 10 means the idea was driven by the market. Likewise, the mean of the degree of idea innovativeness is 6.06 with a standard deviation of 2.71 , where 0 means the idea was essentially a copy and 10 means the idea was the first of its kind. For both the driver and idea innovativeness items, responses cover the complete range of alternatives (except that no projects were rated as a 1 on degree of innovativeness). Thus, the sample reflects a broad range of projects in terms of whether technology or the market drove the idea and the degree of innovativeness.

Early versus late respondents were compared to assess the possibility of response bias (Armstrong and Overton, 1977). The initial $50 \%$ of surveys received were considered early, whereas the remaining $50 \%$ were considered late responses. Using independent sample $t$-tests, no significant differences were found among the mean values for firm size (number of employees), project innovativeness, market competitiveness, and market turbulence. However, other biasing effects were not able to be well modeled, either by comparing with population norms in the demographic variables or in predictive exercises as exemplified by Armstrong and Overton. While response bias cannot be ruled out, enough confirmatory results (discussed next) coincide with similar studies to lend customary confidence in the results.

\section{Measures}

The extant NPD literature was reviewed to identify items to measure the constructs of interest. The dependent variable of product financial performance was measured using two items relating to the product's sales and profits, using an 11-point scale from -5 to +5 . Not only are these metrics often used to assess product performance (Griffin and Page, 1993; Montoya-Weiss and Calantone, 1994), but also a meta-analysis indicates that mean correlations between predictor and outcome variables do not vary with the specific metric for measuring performance (Henard and Szymanski, 2001). Subjective measures are used so the results could be compared across industries.

The operationalizations of the independent variables also used existing scales and were all measured using an 11-point scale ranging from 0 to 10 . The mar- keting discontinuity scale and technological discontinuity scale were adapted from the familiarity items used by Danneels and Kleinschmidt (2001), who found reliability values based on Cronbach's alpha of 0.78 and 0.82 , respectively. Items in both scales were reverse scored to capture discontinuity rather than the familiarity construct measured by Danneels and Kleinschmidt. The customer discontinuity items were adapted from the customer newness scale used by AtuaheneGima (1995), who found a Cronbach's alpha value of 0.78 . These items also were reverse scored to reflect customer discontinuity. The product advantage scale and project protocol scale were adapted from Cooper and Kleinschmidt (1987), who found reliability values of 0.85 and 0.98 , respectively. Based on the reliability values reported by these authors, the scales used are robust as all reliability values exceed 0.70 .

\section{Analysis and Results}

The measures were validated via confirmatory factor analysis (CFA) using EQS Version 6.1 for Windows (Bentler and $\mathrm{Wu}, 1995)$. The CFA results for the measurement model, including the measurement items, standardized factor loadings, and $t$-values, are presented in Table 1. Construct descriptive statistics, including means, standard deviations, factor reliabilities, average variance extracted, and factor correlations, are shown in Table 2.

The measurement model was estimated with items restricted to load on their respective prespecified factors using raw data as input. Items loading less than 0.5 on their respective constructs were removed in successive CFAs (Anderson, 1987). Construct reliability was evaluated by examining the item loadings and their associated $t$-values as well as the factor reliabilities and average variance extracted (Fornell and Larcker, 1981). As shown in Table 1, all loadings in the final CFA were significant with a standardized loading of at least 0.67 and $t$-values larger than 14, evidencing convergent validity (Bagozzi, Yi, and Phillips, 1991). As shown on the diagonal in Table 2, the lowest factor reliability value was 0.79 , indicating reliable factors. The average variance extracted values shown in Table 2 all exceeded $50 \%$, indicating that the measurement error variance was less than the variance captured by the latent variable and that measurement error was not driving the results. The largest correlation between factors was 0.58 between marketing discontinuity and technological discontinuity. All constructs are verified 
Table 1: Confirmatory Factor Analysis Results for the Measurement Model ${ }^{\mathbf{a}}$

\begin{tabular}{|c|c|c|}
\hline Marketing Discontinuity ${ }^{\mathrm{b}}$ & $\lambda$ & $t$-Value \\
\hline $\begin{array}{l}\text { To what extent was the product category an existing one to the company-you had sold } \\
\text { products in this category before now? }\end{array}$ & 0.68 & 14.87 \\
\hline $\begin{array}{l}\text { To what extent were the competitors that this product took you up against familiar ones- } \\
\text { ones you had faced before? }\end{array}$ & 0.84 & 19.40 \\
\hline $\begin{array}{l}\text { To what extent was the distribution or channel system that you used for this product familiar } \\
\text { or an existing one? }\end{array}$ & 0.72 & 15.98 \\
\hline \multicolumn{3}{|l|}{ Technological Discontinuity ${ }^{\mathrm{b}}$} \\
\hline $\begin{array}{l}\text { To what extent could this product be manufactured using existing company plant and } \\
\text { equipment, with no changes required? }\end{array}$ & 0.73 & 17.68 \\
\hline $\begin{array}{l}\text { To what extent was the type of product or manufacturing process a familiar or existing one } \\
\text { for you? }\end{array}$ & 0.97 & 28.25 \\
\hline $\begin{array}{l}\text { To what extent was the technology used in the development of this product familiar or in- } \\
\text { house technology to you? }\end{array}$ & 0.72 & 17.38 \\
\hline \multicolumn{3}{|l|}{ Customer Discontinuity ${ }^{\mathrm{b}}$} \\
\hline $\begin{array}{l}\text { To what extent did this product require little or no change in customer behavior (i.e., way he } \\
\text { used the product or did things)? }\end{array}$ & 0.84 & 18.46 \\
\hline To what extent did this product require little or no "learning" on the part of the customer? & 0.72 & 15.50 \\
\hline $\begin{array}{l}\text { To what extent did this product require little or no change to the customer's own product or } \\
\text { process? }\end{array}$ & 0.67 & 14.39 \\
\hline \multicolumn{3}{|l|}{ Product Advantage } \\
\hline $\begin{array}{l}\text { To what extent was the product superior to competing products in terms of meeting } \\
\text { customers' needs? }\end{array}$ & 0.88 & 22.45 \\
\hline $\begin{array}{l}\text { To what extent was the product quality-however quality is defined by the user-superior to } \\
\text { competitive products? }\end{array}$ & 0.87 & 22.05 \\
\hline $\begin{array}{l}\text { To what extent did the product offer the customer unique attributes or performance } \\
\text { characteristics not available from competitive products? }\end{array}$ & 0.84 & 21.02 \\
\hline $\begin{array}{l}\text { Project Protocol } \\
\text { To what extent was the target market (precisely who the intended customer was) defined prior } \\
\text { to embarking into the development phase of the project? }\end{array}$ & 0.79 & 18.46 \\
\hline $\begin{array}{l}\text { To what extent were the benefits to be delivered defined prior to embarking into the } \\
\text { development phase of the project? }\end{array}$ & 0.77 & 17.86 \\
\hline $\begin{array}{l}\text { To what extent was the positioning strategy (how the product would be positioned in the } \\
\text { market versus competitive products) defined prior to embarking into the development phase } \\
\text { of the project? }\end{array}$ & 0.83 & 19.72 \\
\hline Product Financial Performance & & \\
\hline $\begin{array}{l}\text { To what extent would you rate the product a financial success ... profits clearly exceeded the } \\
\text { minimum acceptable return for projects like this in your company? }\end{array}$ & 0.78 & 17.55 \\
\hline What impact did this product's sales and profits have on the company? & 0.94 & 21.63 \\
\hline
\end{tabular}

${ }^{\mathrm{a}} \chi^{2}=655.18, \mathrm{df}=105, p<.001$; comparative fit index $(\mathrm{CFI})=0.950$; standardized root mean square residual $(\mathrm{SRMR})=0.057$.

${ }^{\mathrm{b}}$ The items are reverse scored.

to be separate factors (i.e., construct discriminant validity) by testing that the latent variable correlations all differed significantly from 1 following the procedure suggested by Bagozzi et al. Although the chi-square statistic was significant at $655.18(\mathrm{df}=105 ; p<.001)$, other fit indices indicated that the measurement model fit the data very well (e.g., CFI $=0.950$, standardized root mean square residual $[\mathrm{SRMR}]=0.057)$.

A CFA-based variant of Harman's one-factor test was employed to actually test for common method bias. If common method bias posed a serious threat to the analysis and interpretation of the data, a single latent factor would account for all manifest variables (Podsakoff and Organ, 1986). A worse fit for the one-factor model versus the hypothesized multiconstruct model would suggest that common method variance does not pose a serious threat (Sanchez, Korbin, and Viscarra, 1995). The singlefactor model yielded the following model fit: $\mathrm{CFI}=0.718$; $\mathrm{SRMR}=0.224 ; \chi^{2}=3232.26 ; \mathrm{df}=120$; $p<.0001$. This fit is significantly inferior to the fit for the (hypothesized) measurement model, providing positive evidence that common method bias was not a serious threat in this study. Further, an examination of covariance across exogenous and endogenous committed manifest variables would reveal the threat of common covariance across the mechanism for probabilistic causal inference. None obtained, allowing free inference of the endogenous constructs by the exogenous constructs in the absence of measure crosscontamination. Next, the hypotheses are assessed via a structural equation model (SEM). 
Table 2: Construct Descriptive Statistics, Reliabilities, and Correlations

\begin{tabular}{|c|c|c|c|c|c|c|}
\hline$N=444$ & 1 & 2 & 3 & 4 & 5 & 6 \\
\hline 1. Marketing Discontinuity & $0.85^{\mathrm{a}}$ & & & & & \\
\hline 2. Technological Discontinuity & $0.58^{* *}$ & 0.79 & & & & \\
\hline 3. Customer Discontinuity & $0.44^{* *}$ & $0.13^{*}$ & 0.79 & & & \\
\hline 4. Product Advantage & -0.01 & -0.10 & $0.27^{* *}$ & 0.90 & & \\
\hline 5. Project Protocol & $-0.20^{* *}$ & $-0.15^{* *}$ & -0.04 & $0.47^{* *}$ & 0.84 & \\
\hline 6. Financial Performance & $-0.40^{* *}$ & $-0.30^{* *}$ & -0.06 & $0.53^{* *}$ & $0.43^{* *}$ & 0.85 \\
\hline Mean $^{\mathrm{b}}$ & 3.73 & 2.46 & 3.73 & 6.67 & 7.81 & 1.12 \\
\hline Standard Deviation & 2.83 & 2.14 & 2.25 & 1.84 & 2.06 & 3.01 \\
\hline Average Variance Extracted (\%) & 56.2 & 66.4 & 55.8 & 74.6 & 63.5 & 74.6 \\
\hline
\end{tabular}

Using the covariance matrix resulting from the CFA of the measurement model as input, the hypotheses were assessed via SEM. The test results are presented in Table 3. The fit indices indicated acceptable overall model fit: $\mathrm{CFI}=0.968 ; \quad \mathrm{SRMR}=0.042$; $\chi^{2}=28.16 ; \mathrm{df}=5 ; p<.001$. All paths were significant except for the path from customer discontinuity to financial performance. While the path from customer discontinuity to financial performance was not significant, the result provided directional support for the hypothesis. However, H1, which suggests a positive link between technological discontinuity and customer discontinuity, was not supported in that the sign is negative. Figure 2 presents the estimated model with the standardized path parameters and corresponding $t$-values in parentheses for each path.

\section{Discussion}

A primary goal of this research is to explain conflicting empirical results regarding the association between product innovativeness and firm performance.
The present research set out to do so by conceptualizing and empirically testing the relationships between three dimensions of product innovativeness-technological discontinuity, marketing discontinuity, and customer discontinuity - and product financial performance. To achieve this goal, first the relationships between the three dimensions was conceptualized, hypothesizing that technological discontinuity and marketing discontinuity are positively associated with customer discontinuity. The empirical test suggested a negative association between technological discontinuity and customer discontinuity while supporting the hypothesized positive association between marketing discontinuity and customer discontinuity.

In this research, technological discontinuity was operationalized as familiarity with development and manufacturing technology and processes rather than as fit with technological capabilities in these realms. Contrary to the direction of the hypothesis, the firmbased construct of technological discontinuity was found to be associated moderately with lower levels of discontinuity for the customer. Based on the present study's results, lack of familiarity with technology

Table 3: Test Results of the Structural Equation Model $^{\mathbf{a}}$

\begin{tabular}{|c|c|c|c|c|}
\hline Path & Hypothesis & Standardized Parameter & $t$-Value & Support \\
\hline Technological Discontinuity $\rightarrow$ Customer Discontinuity & $\mathrm{H} 1(+)$ & -0.152 & -3.101 & no \\
\hline Marketing Discontinuity $\rightarrow$ Customer Discontinuity & $\mathrm{H} 2(+)$ & 0.532 & 10.812 & yes \\
\hline Customer Discontinuity $\rightarrow$ Financial Performance & H3 $(-)$ & -0.037 & -0.874 & directional \\
\hline Marketing Discontinuity $\rightarrow$ Financial Performance & $\mathrm{H} 4(-)$ & -0.376 & -9.281 & yes \\
\hline Product Advantage $\rightarrow$ Customer Discontinuity & $\mathrm{H} 5(+)$ & 0.260 & 6.455 & yes \\
\hline Product Advantage $\rightarrow$ Financial Performance & $\mathrm{H} 6(+)$ & 0.534 & 14.196 & yes \\
\hline Project Protocol $\rightarrow$ Marketing Discontinuity & H7 $(-)$ & -0.195 & -4.185 & yes \\
\hline Project Protocol $\rightarrow$ Technological Discontinuity & H8 $(-)$ & -0.150 & -3.193 & yes \\
\hline Project Protocol $\rightarrow$ Product Advantage & $\mathrm{H} 9(+)$ & 0.470 & 11.207 & yes \\
\hline
\end{tabular}

${ }^{\mathrm{a}} \chi^{2}=28.16, \mathrm{df}=5, p<.001$; comparative fit index $(\mathrm{CFI})=0.968$; standardized root mean square residual $(\mathrm{SRMR})=0.042$. 


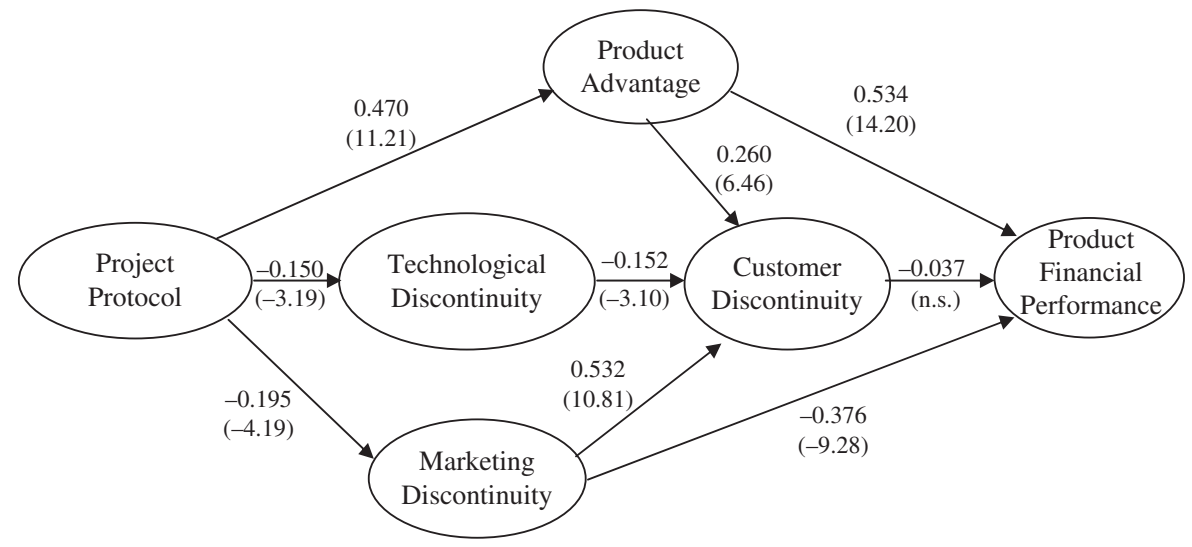

Figure 2: Estimated Path Coefficients for the Model

appears to be a hurdle firms can overcome in developing products, particularly when they implement project protocols that can overcome the detrimental effects of technological discontinuity (Bacon et al., 1994). Also, the contingency plans suggested by Khurana and Rosenthal (1997) can be used to mitigate risks associated with technological discontinuity. Finally, Sood and Tellis (2005) suggest how such a result may occur: when firms maintain a uniform interface to facilitate customer adoption, the use of discontinuous technological innovations in products may not be apparent to customers. The present study's results suggest that technological discontinuities actually can serve to minimize the disruption to customers in terms of their product usage.

At the same time, though, marketing discontinuity was positively associated with customer discontinuity. Danneels (2004) suggests that a reason incumbent firms fail in commercializing disruptive technologies relates less to their familiarity with the technology and more to their "customer competence." Here, customer competence relates to the resources necessary to serve specific customers, such as understanding their needs and buying processes, access to sales and distribution channels, brand and firm reputation among the target groups, and communication channels to the target groups. Indeed, while such firms appear well able to develop working prototypes of products employing disruptive technologies, they often have difficulty effectively promoting the new product to the appropriate sets of customers. Firms fail because they continue to promote to existing customers with whom they are familiar but who may not need or appreciate the innovation. This study's empirical results clearly support this logic. While technological discontinuity can serve to reduce customer discontinuity, marketing discontinuity was associated with increased levels of customer discontinuity, likely due to the lack of familiarity with customers' innovation adoption processes.

Additionally, a goal of this study was to examine empirically the relationships of the three dimensions of product innovativeness to firm performance, product advantage, and project protocols. These results indicated that product advantage was a separate construct from the three dimensions of product innovativeness, as demonstrated by the CFA results. In fact, product advantage was found not to be correlated with the firm-based innovativeness dimensions of technological discontinuity and marketing discontinuity. In addition, product advantage was only moderately correlated with customer discontinuity. The SEM analysis supported the hypothesis that product advantage exhibits a significant association with customer discontinuity. Clearly, the more advantageous the product, the more likely customers will experience a disruption in their use of the product, requiring learning about the product and changes in their usage behavior.

Simultaneously, the present study's results provide further evidence for the well-supported positive relationship between product advantage and financial performance. However, contrary to Calantone et al. (2006), the relationship between customer discontinuity and financial performance was found here to be insignificant. Finally, financial performance was hindered by marketing discontinuity, which is lack of familiarity with the product category, competitors, and distribution channels, a result contrary to that found by Danneels and Kleinschmidt (2001). The contribution here is that the present study tests the explanatory power of all three constructs at once. By 
doing so, further evidence was found for the importance of product advantage, even when considered with multiple dimensions of product innovativeness. Not only is it important for product financial performance that products deliver, for example, superior quality, benefits, and value, but also differences in the effect sizes provided evidence that product advantage can mitigate the disadvantages a firm faces when launching a product into a new market.

Given the importance of product advantage and the need to mitigate the harmful product financial impact of marketing discontinuity, managers will be happy to know that project protocols are useful in achieving both objectives. The long-recommended practice of developing a project protocol-or an agreed upon document identifying product benefits to be delivered, a well-defined target market, and clear product positioning - enhances product advantage and reduces marketing discontinuities. At the same time, project protocols also reduced technological discontinuities. Clearly identifying the project deliverables and target market may help firms identify existing technology, equipment, and processes in both development and manufacturing that can be used with the new product. Thus, the present research contributes to the NPD literature as it supports the notion that having agreed NPD project priorities prior to development helps reduce the uncertainty associated with working with unfamiliar technology and markets while at the same time enhancing product advantage.

\section{Managerial Implications}

The model shown in Figure 2 suggests a complex set of relationships surrounding product innovativeness dimensions and their impact on firm performance. However, the total effects model included in Figure 3 suggests a straightforward and useful way for managers to think about the results. The total effects model accounts for both the direct effects of the five independent variables on firm performance as well as the indirect effects occurring through mediation. The total effects model shows that the three constructs of product advantage, marketing discontinuity, and project protocol impacted firm performance, whereas customer discontinuity and technological discontinuity had no effect.

As in the more complicated path model, the total effects model highlights the substantial contribution of product advantage to firm performance. In addition, the total effects model suggests product advantage can overcome the disadvantages associated with operating in new marketing domains as when, for example, the product category, competitors, distribution channels, or customers are unfamiliar to the firm. What the total effects model contributes beyond the more complicated path model is the important role of the project protocol. Although not linked directly to firm performance, the indirect effects of project protocols were positive and contributed substantially to firm performance.

Furthermore, the total effects model helps clarify the roles of technological discontinuity and customer discontinuity. First, as stated earlier, the empirical result for $\mathrm{H} 1$ was opposite in sign than that hypothesized, a result assumed to arise due to the benefits of the project protocol. Managers are surmised not to need to be concerned with implementing innovation projects based on unfamiliar technology if they do their homework and create a project protocol that describes and prioritizes the required elements. In addition, customer discontinuity did not appear to be a

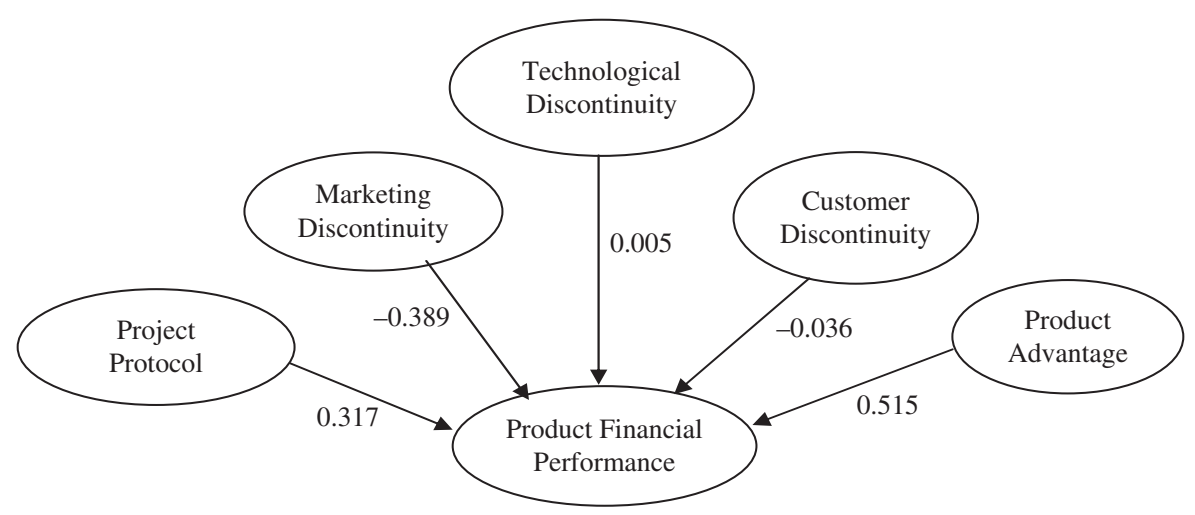

Figure 3: Total Effects Diagram 
problem in product financial performance when product advantage existed.

Thus, the important implications for managers of this research are twofold. First, even though innovative products often disrupt customer usage behavior, requiring customers to learn new ways of addressing their needs, the disruption ultimately is not harmful to firm performance as long as the product delivers advantages to customers. Second, while the uncertainties associated with serving new markets reduce firm performance, the use of project protocols is an important driver of firm performance by offsetting these uncertainties. Project protocols are useful because they reduce problems associated with firms' unfamiliarity with new technology and markets and they enhance the advantage of the products firms deliver to the market.

\section{Future Research and Limitations}

The approach and empirical findings of this study provide a platform for a variety of future research efforts. For example, comparative studies between domestic and international strategies would provide insight into whether standardization of strategic innovation approaches is beneficial or detrimental to firm performance. With the increasing importance of research in the areas of innovation and outsourced innovation across multiple markets, along with the limited understanding of strategic marketing functions in an international domain, future studies relative to innovativeness could also assist firms fitting NPD strategy responsibilities with the most appropriate task portfolio.

This research is limited to a certain degree, however, by its focused investigation on actual decision variables. While significant results indicated that strategic congruence was critical in most instances, the small proportion of variance explained in the models clearly shows that other factors are involved in achieving performance goals. In fact, this result calls for a study of a more holistic strategy congruence model to understand the validity of the underlying assumptions of strategic congruence.

Another category of limitations relates to the operationalization of the variables. The first operationalization issue pertains to customer discontinuity. Customer discontinuity is conceptualized here as related to newness in terms of customer process changes and learning. Meaningfulness is not included in this conceptualization, but it has been shown to result in more significant relationships between customer innovativeness and product financial performance (Szymanski et al., 2007). Future research could incorporate both newness and meaningfulness into the customer discontinuity conceptualization, which may yield a significant relationship for the customer discontinuity-product financial performance relationship.

The other operationalization issue relates to the marketing discontinuity and technological discontinuity measures. Only familiarity items were employed without considering fit or synergy. This could be an important area as lack of familiarity appeared to be overcome with the use of project protocols. Would an operationalization using fit measures find the same result? That is, can project protocols overcome problems associated with applying new technologies that have no synergy with existing capabilities? Future research should address this issue.

Finally, subjective measures of firm performance and managers' perceptions of customer discontinuity were used. Prior research suggests a difference in construct relationships when objective performance measures are used instead of subjective performance measures (Henard and Szymanski, 2001). Future research should use objective performance measures. Also, Danneels and Kleinschmidt (2001) observe that customers should report on customer discontinuity rather than using manager reports. Future research is suggested that employs reports from multiple respondents - managers for firm constructs and customers for customer constructs of product advantage and customer discontinuity.

\section{Conclusions}

The present study set out to address conflicting findings regarding the relationship between product innovativeness and firm performance by conceptualizing product innovativeness as consisting of three discontinuity dimensions. Although the three dimensions of technological discontinuity, marketing discontinuity, and customer discontinuity are linked conceptually and empirically, these results suggest that only marketing discontinuity is related significantly and negatively to firm performance. On a positive note, however, although the uncertainties associated with entering new markets were found to harm performance, this result can be more than offset through using project protocols to deliver products exhibiting competitive advantages. 


\section{References}

Alexander, D.L., Lynch, J.G., and Wang, Q. (2007). As Time Goes By: Warm Intentions and Cold Feet for Really New versus Incrementally New Products? Cambridge: Marketing Science Institute, Report \# 07-112.

Anderson, J.C. (1987). An Approach for Confirmatory Measurement and Structural Equation Modeling of Organizational Properties. Management Science 33(4):525-541.

Armstrong, J.S. and Overton, T.S. (1977). Estimating Nonresponse Bias in Mail Surveys. Journal of Marketing Research 14(3):396-402.

Atuahene-Gima, K. (1995). An Exploratory Analysis of the Impact of Market Orientation on New Product Performance: A Contingency Approach. Journal of Product Innovation Management 12(4): 275-294.

Atuahene-Gima, K., Slater, S.F., and Olson, E.M. (2005). The Contingent Value of Responsive and Proactive Market Orientations for New Product Program Performance. Journal of Product Innovation Management 22(6):464-482.

Bacon, G., Beckman, S., Mowery, D., and Wilson, E. (1994). Managing Product Definition in High-Technology Industries: A Pilot Study. California Management Review 36(3):32-56.

Bagozzi, R.P., Yi, Y., and Phillips, L.W. (1991). Assessing Construct Validity in Organizational Research. Administrative Science Quarterly 36(3):421-458.

Bentler, P.M. and Wu, E.J.C. (1995). EQS for Windows User's Guide. Encino, CA: Multivariate Software, Inc.

Calantone, R.J., Chan, K., and Cui, A.S. (2006). Decomposing Product Innovativeness and Its Effects on New Product Success. Journal of Product Innovation Management 23:408-421.

Calantone, R., Di Benedetto, A., and Bhoovaraghavan, S. (1994). Examining the Relationship Between Degree of Innovation and New Product Success. Journal of Business Research 30(2):143-148.

Carpenter, G.S. and Nakamoto, K. (1989). Consumer Preference Formation and Pioneering Advantage. Journal of Marketing Research 26(3):285-298.

Chandy, R.K. and Tellis, G.J. (1998). Organizing for Radical Product Innovation: The Overlooked Role of Willingness to Cannibalize. Journal of Marketing Research 35(4):474-487.

Chandy, R.K. and Tellis, G.J. (2000). The Incumbent's Curse? Incumbency, Size, and Radical Product Innovation. Journal of Marketing 64(3):1-17.

Cooper, R.G. (1979). The Dimensions of Industrial New Product Success and Failure. Journal of Marketing 43(3):93-103.

Cooper, R.G. and Kleinschmidt, E.J. (1986). An Investigation into the New Product Process: Steps, Deficiencies, and Impact. Journal of Product Innovation Management 3:71-85.

Cooper, R.G. and Kleinschmidt, E.J. (1987). New Products: What Separates Winners from Losers? Journal of Product Innovation Management 4(3):169-184.

Crawford, C.M. (1984). Protocol: New Tool for Product Innovation. Journal of Product Innovation Management 1(2):85-91.

Dahl, D.W. and Hoeffler, S. (2004). Visualizing the Self: Exploring the Potential Benefits and Drawbacks for New Product Evaluation. Journal of Product Innovation Management 21:259-267.

Danneels, E. (2004). Disruptive Technology Reconsidered: A Critique and Research Agenda. Journal of Product Innovation Management 21(4):246-258.

Danneels, E. and Kleinschmidt, E.J. (2001). Product Innovativeness from the Firm's Perspective: Its Dimensions and Their Relation with Project Selection and Performance. Journal of Product Innovation Management 18(6):357-373.

De Brentani, U. (1989). Success and Failure in New Industrial Services. Journal of Product Innovation Management 6(4):239-258.
Fornell, C. and Larcker, D.F. (1981). Evaluating Structural Equation Models with Unobservable Variables and Measurement Error. Journal of Marketing Research 18(1):39-50.

Garcia, R. and Calantone, R. (2002). A Critical Look at Technological Innovation Typology and Innovativeness Terminology: A Literature Review. Journal of Product Innovation Management 29:110132.

Gatignon, H. and Xuereb, J. (1997). Strategic Orientation of the Firm New Product Performance. Journal of Marketing Research 34(1):77-90.

Gatignon, H., Tushman, M.L., Smith, W., and Anderson, P. (2002). A Structural Approach to Assessing Innovation: Construct Development of Innovation Locus, Type, and Characteristics. Management Science 48(9): 1103-1122.

Govindarajan, V. and Kopalle, P.K. (2006). Disruptiveness of Innovations: Measurement and an Assessment of Reliability and Validity. Strategic Management Journal 27(2):189-199.

Griffin, A. and Page, A.L. (1993). An Interim Report on Measuring Product Development Success and Failure. Journal of Product Innovation Management 10:291-308.

Henard, D.H. and Szymanski, D.M. (2001). Why Some New Products Are More Successful than Others. Journal of Marketing Research 38(3):362-275.

Hoeffler, S. (2003). Measuring Preferences for Really New Products. Journal of Marketing Research 40(4):406-420.

Hoeffler, S., Ariely, D., and West, P. (2006). Path Dependent Preferences: The Role of Early Experience and Biased Search in Preference Development. Organizational Behavior and Human Decision Processes 101(2):215-229.

Holak, S.L. and Lehmann, D.R. (1990). Purchase Intentions and the Dimensions of Innovation: An Exploratory Model. Journal of Product Innovation Management 7:59-73.

Karlsson, C., Nellore, R., and Soderquist, K. (1998). Black Box Engineering: Redefining the Role of Product Specifications. Journal of Product Innovation Management 15:534-549.

Kleinschmidt, E.J. and Cooper, R.G. (1991). The Impact of Product Innovativeness on Performance. Journal of Product Innovation Management 8:240-251.

Khurana, A. and Rosenthal, R. (1997). Integrating the Fuzzy Front End of New Product Development. Sloan Management Review 38(2):103-120.

Langerak, F., Hultink, E.J., and Robben, H.S.J. (2004). The Impact of Marketing Orientation, Product Advantage, and Launch Proficiency on New Product Performance and Organizational Performance. Journal of Product Innovation Management 21: 79-94.

Li, T. and Calantone, R.J. (1998). The Impact of Market Knowledge Competence on New Product Advantage: Conceptualization and Empirical Examination. Journal of Marketing 62(4):13-29.

MacInnis, D.J. and Price, L.L. (1987). The Role Of Imagery in Information Processing: Review and Extensions. Journal of Consumer Research 13(4):473-491.

Min, S., Kalwani, M.U., and Robinson, W.T. (2006). Market Pioneer and Early Follower Survival Risks: A Contingency Analysis of Really New Versus Incrementally New Product Markets. Journal of Marketing 70(1):15-33.

Montoya-Weiss, M.M. and Calantone, R. (1994). Determinants of New Product Performance: A Review and Meta-Analysis. Journal of Product Innovation Management 11:397-417.

Moreau, C.P., Lehmann, D.R., and Markman, A.B. (2001). Entrenched Knowledge Structures and Consumer Responses to New Products. Journal of Marketing Research 38(1):14-29.

O'Connor, G.C. (2008). Major Innovation as a Dynamic Capability: A Systems Approach. Journal of Product Innovation Management 28(4):313-330. 
O'Connor, G.C. and McDermott, C.M. (2004). The Human Side of Radical Innovation. Journal of Engineering and Technology Management 21(1-2):11-30.

Podsakoff, P.M. and Organ, D.W. (1986). Self-Reports in Organizational Research: Problems and Prospects. Journal of Management 12(4):531-544.

Rogers, E.M. (1995). Diffusion of Innovations, (4th ed.). New York: Free Press.

Saaksjarvi, M. (2003). Consumer Adoption of Technological Innovations. European Journal of Innovation Management 6(2):90-100.

Salomo, S., Weise, J., and Gemunden, H.G. (2007). NPD Planning Activities and Innovation Performance: The Mediating Role of Process Management and the Moderating Effect of Product Innovativeness. Journal of Product Innovation Management 24:285-302.

Sanchez, J.I., Korbin, W.P., and Viscarra, D.M. (1995). Corporate Support in the Aftermath of a Natural Disaster: Effects on Employee Strains. Academy of Management Journal 38:504-521.

Song, X.M. and Montoya-Weiss, M.M. (2001). The Effects of Perceived Technological Uncertainty on Japanese New Product Development. Academy of Management Journal 44(1):61-80.

Song, X.M. and Parry, M.E. (1996). What Separates Japanese New Product Winners from Losers. Journal of Product Innovation Management 13(5):422-439.

Song, X.M. and Parry, M.E. (1997a). The Determinants of Japanese New Product Successes. Journal of Marketing Research 34(1):64-76.

Song, X.M. and Parry, M.E. (1997b). A Cross-National Comparative Study of New Product Development Processes: Japan and the United States. Journal of Marketing 61(2):1-18.

Sood, A. and Tellis, G.J. (2005). Technological Evolution and Radical Innovation. Journal of Marketing 69(3):152-174.
Sorescu, A.B. and Spanjol, J. (2008). Innovation's Effect on Firm Value and Risk: Insights from Consumer Packaged Goods. Journal of Marketing 72(2):114-132.

Souder, W.E. and Jenssen, S. (1999). Management Practices Influencing New Product Success and Failure in the United States and Scandinavia: A Cross-Cultural Comparative Study. Journal of Product Innovation Management 16:183-203.

Souder, W.E. and Song, X.M. (1998). Analyses of U.S. and Japanese Management Processes Associated with New Product Success and Failure in High and Low Familiarity Markets. Journal of Product Innovation Management 15:208-223.

Szymanski, D.M., Kroff, M.W., and Troy, L.C. (2007). Innovativeness and New Product Success: Insights from the Cumulative Evidence. Journal of the Academy of Marketing Science 35:35-52.

Tushman, M.L. and Romanelli, E. (1985). Organization Evolution: A Metamorphosis Model of Convergence and Reorientation. Organizational Behavior 7:171-222.

Veldhuizen, E., Hultink, E.J., and Griffin, A. (2006). Modeling Marketing Information Processing in New Product Development: An Empirical Analysis. Journal of Engineering and Technology Management 23:353-373.

Veryzer Jr., R.W. (1998). Discontinuous Innovation and the New Product Development Process. Journal of Product Innovation Management 15(4):304-321.

Zhao, M., Hoeffler, S., and Dahl, D.W. (2009). The Role of Imagination-Focused Visualization on New Product Evaluation. Journal of Marketing Research 46:46-55.

Zirger, B.J. and Maidique, M.A. (1990). A Model of New Product Development: An Empirical Test. Management Science 36(7): $867-883$. 